\title{
Free Radical Scavenging, Membrane Stabilizing and Thrombolytic Potentials of the Leaves of Quisqualis indica (L.)
}

\author{
Farhana Ahmed, Fahima Aktar, Mohammad A. Rashid and \\ Mohammad Sharifur Rahman
}

Department of Pharmaceutical Chemistry, Faculty of Pharmacy, University of Dhaka, Dhaka-1000, Bangladesh

(Received: April 9, 2020; Accepted: May 15, 2020; Published (Web): May 22, 2021)

\begin{abstract}
Bangladesh is a land of thousands of plants which might provide a scope to obtain therapeutically important natural drugs. Systematic screening of plants is very vital to fulfill this goal. Quisqualis indica (L.) is a vine and it belongs to the Combretaceae family. It grows all over the Bangladesh. It has some local uses to treat headache, skin disease, diarrhea, fever, cough, etc. In order to assess its biological potential, the leaves of the plant were collected and subjected to methanol extraction followed by fractionating into petroleum ether, carbon tetrachloride, chloroform and aqueous soluble materials. Primary free radical scavenging power of the extractives was evaluated using the radicals generated by DPPH and $\mathrm{H}_{2} \mathrm{O}_{2}$. Methanol crude extract as well as aqueous and chloroform fractions showed noticeable radical scavenging potential. Besides, these extracts had higher level of phenolics. The membrane stabilizing potential of the extractives was estimated based on the prevention of hemolysis of RBC prompted by hypotonic solution as well as heat. The aqueous fraction showed the highest level of membrane stabilizing potential indicating its primary anti-inflammatory ability. The extractives were also subjected to thrombolytic study. Mild thrombolytic ability was displayed by them compared to the standard. Further studies are required to explore bioactive compounds.
\end{abstract}

Key words: Quisqualis indica, Free radical scavenging, DPPH, Hydrogen peroxide, Phenolic, Membrane stabilizing, Thrombolytic.

\section{Introduction}

Medicinal plants serve as vital sources of lead molecules. A significant portion of the existing drugs are the natural products or derivatives of natural products. In this aspect, screening of the bioactivity and phytochemical of the plants is essential to proceed for drug discovery from natural sources. Bangladesh is a land of varieties of plants which provide an opportunity to obtain pharmacologically important extracts leading to drug discovery (Rahman et al., 2008).

Free radicals generated in cell drastically damage nucleic acids, carbohydrates, protein, fats, etc. It might also trigger multiple complexities like inflammation, mutation, cancer, etc. Antioxidant capable of scavenging free radicals might be useful to counteract these disorders. Inflammation is always a concern during many pathological states (Clement and Luo, 2020). To find better anti-inflammatory drugs, numerous candidates always remain in the process of screening (Colebatch et al., 2012). Thrombosis is a very critical issue for patients with vascular diseases as it can lead to death gradually. Drugs, diets, life style changes, etc. are always tried to counteract thrombolytic disorders (Hilleman and Campbell, 2011). Regarding all of the abovementioned issues, natural products are getting priority to discover new lead molecules (Abu Bakar et al., 2018; Pisoschi et al., 2016; Shilpi et al., 2012; Yan et al., 2015). In this context, plants of Bangladesh should be screened in a methodical way to explore their biological potentials.

Corresponding author: Mohammad Sharifur Rahman, Email: msr@ du.ac.bd

DOI: https://doi.org/10.3329/bpj.v24i2.54707 
Quisqualis indica L. (family- Combretaceae; English name- Rangoon-creeper, Chinese honeysuckle; Bangla name- Basantilata, Madhabilata, Modhumalati, Modhumanjuri) is a shrubby vine having light pink to crimson star shaped flowers (Sahu et al., 2012). Leaves of $Q$. indica reported to have quisqualic acid, trigonelline, L-proline, rutin, Lasparagine and cysteine synthase. Pelargonidin-3glucoside and rutin were isolated from flowers. Seeds contain linoleic acid, palmitic acid, oleic acid, stearic acid, arachidic acids, quisqualic acid and so on (Ghani, 2003; Rastogi and Mehrotra, 1990 and 1993). Analgesic, antimicrobial, immunomodulatory, antidiarrheal, anti-staphylococcal and hypolipidemic effects, etc. have been reported earlier (Jahan et al., 2008; Jahan et al., 2009; Kulshreshtha et al., 2018; Sahu et al., 2012). The plant is traditionally used for treating headache, skin disease, diarrhea, fever, cough, flatulent distention of the abdomen, etc. (Mahajan and Aher, 2017; Sahu et al., 2012). Earlier, a study on the stem bark of $Q$. indica showed some potentials as antioxidant (Kaisar et al., 2009). Besides, a free radical scavenging assay was performed with the polar parts of the leaves $Q$. indica but low polar fraction was not prepared and evaluated (Bose et al., 2009). The current investigation was designed to assess comprehensively the free radical scavenging, membrane stabilizing and thrombolytic potentials of leaves of $Q$. indica using various fractions of different polarities.

\section{Materials and Methods}

Chemicals: acetylsalicylic acid, gallic acid, hydrogen peroxide, 2,2'-diphenyl-1-picrylhydrazyl radical (DPPH) and quercetin were procured from Sigma-Aldrich Co., St. Louis, USA. FolinCiocalteu's reagent and ascorbic acid were collected from Loba Chemie Pvt. Ltd., Mumbai, India.

Plant collection and extraction: Leaves of Quisqualis indica (L.) was collected from Curzon hall, Dhaka in June, 2014. A voucher specimen for $Q$. indica (L.) with DACB Accession No: 40167 have been deposited at Bangladesh National Herbarium (BNH), Mirpur Road-1, Dhaka for future references.
$500 \mathrm{~g}$ of leaf was powdered and macerated by $2.5 \mathrm{~L}$ of methanol for 2 weeks at RT (room temperature) followed by filtering using Whatman filter paper number 1 and concentrating to obtain methanol crude extracts (MCE). $5 \mathrm{~g}$ of this was fractionated into petroleum ether (PE, $2.8 \mathrm{~g}$ ), carbon tetrachloride (CTC, $1.8 \mathrm{~g}$ ), chloroform (CF, $0.15 \mathrm{~g}$ ) and aqueous $(\mathrm{AQ}, 0.25 \mathrm{~g})$ soluble materials as per modified Kupchan method (VanWagenen et al., 1993).

$D P P H$ free radical scavenging assay: Extracts (500-0.977 $\mu \mathrm{g} / \mathrm{ml}$ methanol) were mixed separately with DPPH $(20 \mu \mathrm{g} / \mathrm{ml}$ methanol) at 2:3 (v/v), incubated for 20 minutes (at dark, RT). The absorbance was measured at $517 \mathrm{~nm}$. The concentration required to inhibit $50 \%$ of radical $\left(\mathrm{IC}_{50}\right)$ by plotting the \% inhibition of radical against extract concentrations (Chaity et al., 2016).

$\mathrm{H}_{2} \mathrm{O}_{2}$ free radical scavenging assay: $3.4 \mathrm{ml}$ of extracts $(500-0.977 \mu \mathrm{g} / \mathrm{ml})$ was taken to $0.6 \mathrm{ml}$ of 40 $\mathrm{mM} \mathrm{H} \mathrm{H}_{2} \mathrm{O}_{2}$ separately, incubated for $10 \mathrm{~min}$ at RT and absorbance was taken at $230 \mathrm{~nm}$ to calculate $\mathrm{IC}_{50}$ (Ahmed and Rahman, 2016).

Phenolic content determination: It was estimated by using Folin-Ciocalteu reagent. Total phenolics were stated as $\mathrm{mg}$ of gallic acid equivalent (GAE) / $\mathrm{g}$ of the extract (Ahmed and Rahman, 2016).

Determination of membrane stabilizing activity: It was evaluated by utilizing hypotonic solution- and heat- induced RBC hemolysis (Shinde et al., 1999). In case of hypotonic solution- induced hemolysis, 0.5 $\mathrm{ml}$ of RBC suspension, $5 \mathrm{ml}$ of $50 \mathrm{mM} \mathrm{NaCl}$ as hypotonic solution and plant sample $(1 \mathrm{mg} / \mathrm{ml})$ or acetylsalicylic acid (standard) $(0.1 \mathrm{mg} / \mathrm{ml})$ were put together and kept at RT (10 min), centrifuged (3000 g for $10 \mathrm{~min}$ ) and the optical density (OD) of the supernatants were estimated at $540 \mathrm{~nm}$. \% inhibition of $\mathrm{RBC}$ hemolysis was calculated as $\left\{\left(\mathrm{OD}_{\text {control }}-\right.\right.$ $\left.\left.\mathrm{OD}_{\text {test }}\right) / \mathrm{OD}_{\text {control }}\right\} \times 100$. In case of heat- induced $\mathrm{RBC}$ hemolysis, $5 \mathrm{ml}$ of isotonic buffer, extractive (1 $\mathrm{mg} / \mathrm{ml})$ or acetylsalicylic acid $(0.1 \mathrm{mg} / \mathrm{ml})$ and $\mathrm{RBC}$ suspension $(30 \mu \mathrm{l})$ was put into a tube. One group of the tubes along with control samples were kept at 54 ${ }^{\circ} \mathrm{C}$ (20 min), while another group of samples were kept at $0-5{ }^{\circ} \mathrm{C}$. It was then centrifuged $(1300 \mathrm{~g}, 3 \mathrm{~min})$ 
and OD of the supernatants were estimated at 540 nm. \% Inhibition of RBC hemolysis was $\{1-$ $\left(\mathrm{OD}_{\text {heated test }}-\mathrm{OD}_{\text {unheated test }}\right) /\left(\mathrm{OD}_{\text {heated control }}-\mathrm{OD}_{\text {heated }}\right.$ test) \} x 100.

Determination of thrombolytic activity: The required clot was produced from human venous blood. Extractive ( $1 \mathrm{mg} / 100 \mu \mathrm{l}$ water) was included to clot $\left(37^{\circ} \mathrm{C}, 90\right.$ minutes). Streptokinase $(100 \mu \mathrm{l}$, equivalent to 30,000 IU) (Beacon pharmaceuticals Limited, Bangladesh) was taken as positive control (Prasad et al., 2006).

Statistical analysis: Values are presented as mean \pm standard deviation $(\mathrm{n}=3)$.

\section{Results and Discussion}

Free radicals are perilous elements to cause biological havoc by damaging macromolecules. It can initiate the cascade of biochemical reactions to cause cancer, inflammation, oxidative stress and so on. Many natural products have been proved to contain potent radical scavengers (Nimse and Pal, 2015). Free radical scavenging assay might be a useful tool to identify the plant extracts having potent radical scavenging power (Nigri et al., 2004; Schetter et al., 2010). In the present study, the free radicals were generated from DPPH and $\mathrm{H}_{2} \mathrm{O}_{2}$ to screen radical inhibitory potential of the plant materials. In the DPPH assay (Fig. 1A), different extractives of $Q$. indica also showed noteworthy free radical scavenging property. The methanol crude extract showed the maximum scavenging activity having $\mathrm{IC}_{50}=$ of $9.73 \mu \mathrm{g} / \mathrm{ml}$. Among the fractions the aqueous fraction showed noticeable radical scavenging $\left(\mathrm{IC}_{50}=11.73 \mu \mathrm{g} / \mathrm{ml}\right)$. The radical scavenging ability can be ordered as MCE > AQ > $\mathrm{CF}>\mathrm{CTC}>\mathrm{PE}$. In the $\mathrm{H}_{2} \mathrm{O}_{2}$ assay (Fig. 1B), the methanol crude extract also showed highest free radical scavenging activity $\left(\mathrm{IC}_{50}=201.85 \mu \mathrm{g} / \mathrm{ml}\right.$ ). The order of antioxidant activity displayed here can be presented as MCE $>\mathrm{CF}>\mathrm{AQ}>\mathrm{CTC}>\mathrm{PE}$.
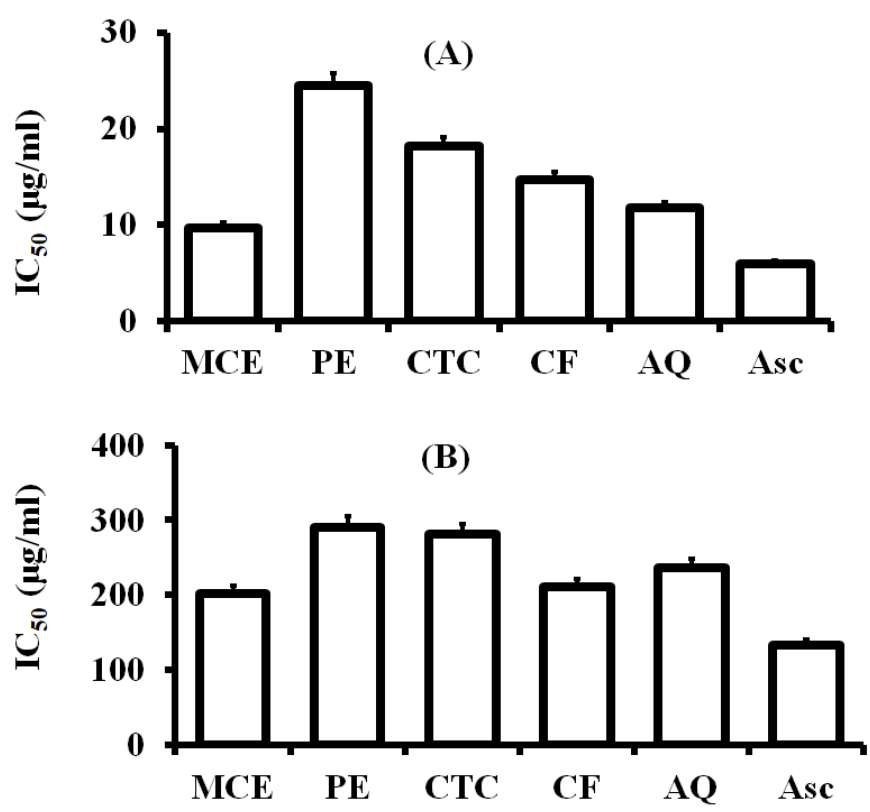

Figure $1 . \mathrm{IC}_{50}$ values of the extracts of $Q$. indica in (A) DPPH free radical scavenging and (B) $\mathrm{H}_{2} \mathrm{O}_{2}$ free radical scavenging assays. Asc, Ascorbic acid (standard).

Phenolic compounds are known as potent antioxidants. They are also known as free radical scavengers. The level of phenolic contents might act as an important clue to predict the radical scavenging potential of any extract (Huyut et al., 2017). In the current study, the upmost level of phenolics was 
found in the MCE. The order of the level of phenolics in the extracts can be assigned as $\mathrm{MCE}>\mathrm{AQ}>\mathrm{CF}>$ CTC > PE (Fig. 2). The potent radical scavenging ability of MCE, AQ and CF might be linked with level of total phenolic contents to some extent (Baharfar et al., 2015).

Many anti-inflammatory agents (extracts and compounds) have been marked from nature (Aswad et al., 2018; Maroon et al., 2010). Erythrocyte membrane stabilization assay is a tool to recognize the primary anti-inflammatory effect of plant extractives based on the prevention of hemolysis mimicking the protection of the lysozyme membrane. If lysozyme is released, it might stimulate the inflammatory mediators like prostaglandins, free radicals, etc. (Chou, 1997). In the hypotonic solution induced assay, the highest level of inhibition of hemolysis was displayed by aqueous fraction (71.50 $\%)$. The order of the membrane protection potential can be ordered as AQ > MCE > CF > PE > CTC. In the heat induced hemolysis assay, the aqueous fraction also showed the highest level inhibition of hemolysis $(39.46 \%)$. The order of inhibition of hemolysis is $\mathrm{AQ}>\mathrm{CF}>\mathrm{MCE}>\mathrm{PE}>\mathrm{CTC}$.

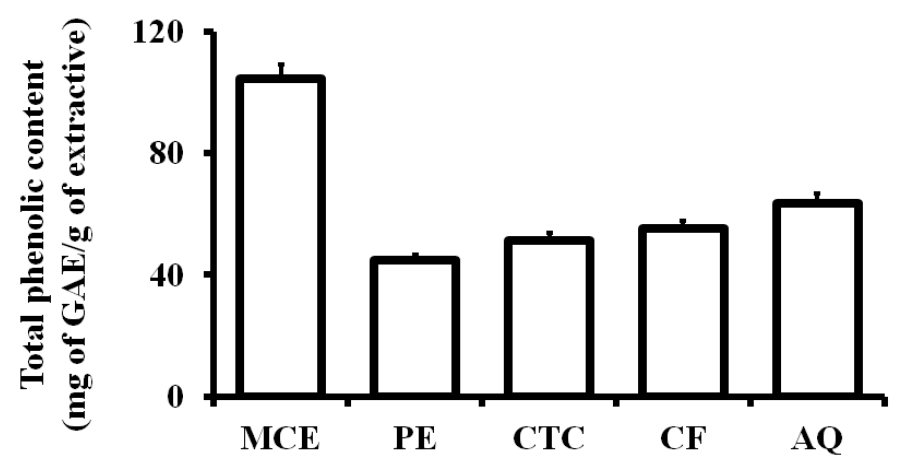

Figure 2. Total phenolic contents of different extractives of $Q$. indica.
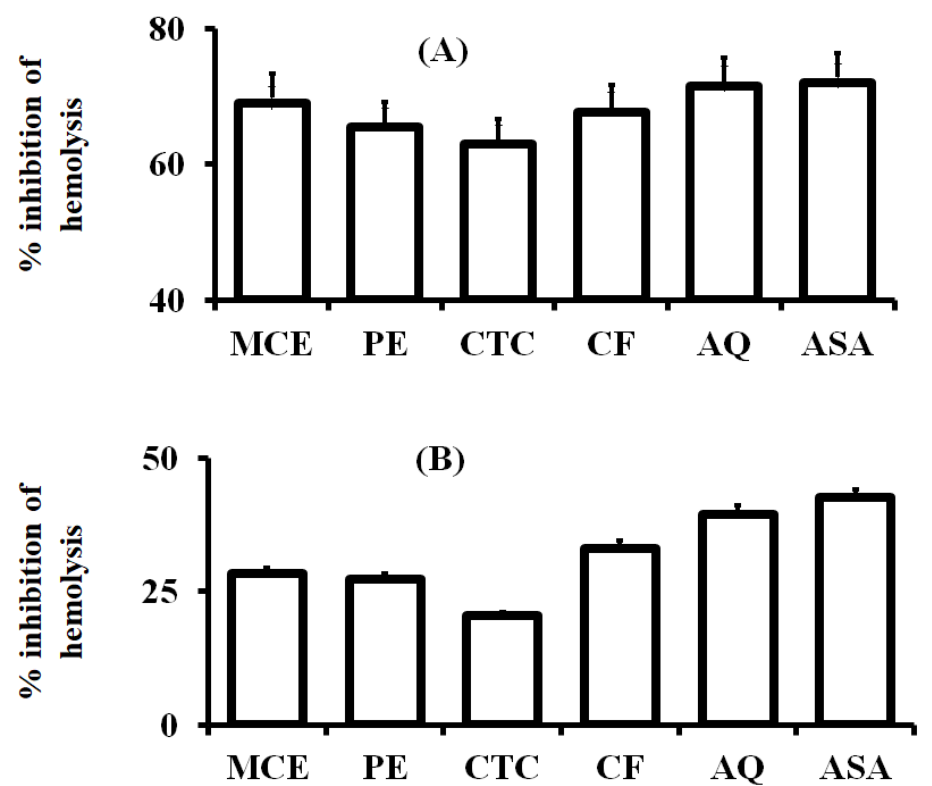

Figure 3. \% inhibition of hemolysis of RBC by different extractives of $Q$. indica in hypotonic solution- (A) and heat- (B) induced conditions. ASA, Acetylsalicylic acid (standard). 
Clot lytic potential of plants can be utilized for patients with thrombosis (Furie and Furie, 2008). Here, different extractives of $Q$. indica showed very weak clot lysis activity in compare to streptokinase (standard). Among different fractions, the carbon tetrachloride soluble fraction showed the highest clot lysis activity of $25.92 \%$.

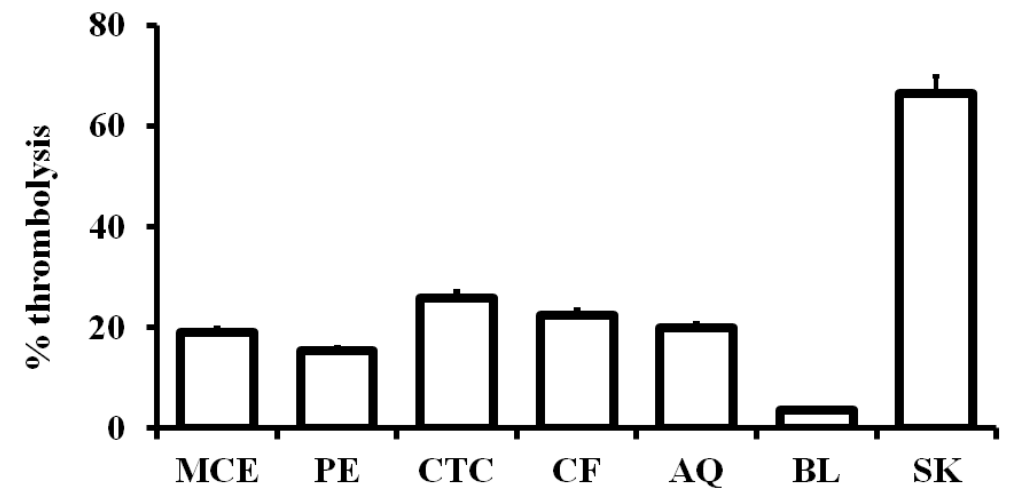

Figure 4. \% clot lysis of different extractives of $Q$. indica. BK, Blank (water); SK, Streptokinase.

\section{Conclusion}

The present study comprehensively investigated the leaves of $Q$. indica. The methanol extract of the leaves and its different organic fractions exhibited noticeable free radical scavenging power as well as membrane stabilizing capacity. However, their thrombolytic actions were very weak. Further detail studies are required to identify the bioactive molecules.

\section{References}

Abu Bakar, F.I., Abu Bakar, M.F., Abdullah, N., Endrini, S. and Rahmat, A. 2018. A review of malaysian medicinal plants with potential anti-inflammatory activity. Adv. Pharmacol. Sci. 2018, 8603602.

Ahmed, F. and Rahman, M.S. 2016. Preliminary assessment of free radical scavenging, thrombolytic and membrane stabilizing capabilities of organic fractions of Callistemon citrinus (Curtis.) skeels leaves. BMC Complement. Altern. Med. 16, 247.

Aswad, M., Rayan, M., Abu-Lafi, S., Falah, M., Raiyn, J., Abdallah, Z. and Rayan, A. 2018. Nature is the best source of anti-inflammatory drugs: indexing natural products for their anti-inflammatory bioactivity. Inflamm. Res. 67, 67-75.
Baharfar, R., Azimi, R. and Mohseni, M. 2015. Antioxidant and antibacterial activity of flavonoid-, polyphenoland anthocyanin-rich extracts from Thymus kotschyanus boiss \& hohen aerial parts. J. Food Sci. Technol. 52, 6777-6783.

Bose, A., Bose, S., Maji, S. and Chakraborty, P. 2009. Free radical scavenging property of Quisqualis indica. Int. J. Biomed. Pharmaceut. Sci. 3, 1-4.

Chaity, F.R., Khatun, M. and Rahman, M.S. 2016. In vitro membrane stabilizing, thrombolytic and antioxidant potentials of Drynaria quercifolia L., a remedial plant of the Garo tribal people of Bangladesh. BMC Complement. Altern. Med. 16, 184.

Chou, C.-T. 1997. The antiinflammatory effect of an extract of Tripterygium wilfordii Hook F on adjuvantinduced paw oedema in rats and inflammatory mediators release. Phytother. Res. 11, 152-154.

Clement, M.V. and Luo, L. 2020. Organismal aging and oxidants beyond macromolecules damage. Proteomics. 20, e1800400.

Colebatch, A.N., Marks, J.L., van der Heijde, D.M. and Edwards, C.J. 2012. Safety of nonsteroidal antiinflammatory drugs and/or paracetamol in people receiving methotrexate for inflammatory arthritis: a Cochrane systematic review. J. Rheumatol. Suppl. 90, 62-73.

Furie, B. and Furie, B.C. 2008. Mechanisms of thrombus formation. N. Engl. J. Med. 359, 938-949. 
Hilleman, D. and Campbell, J. 2011. Efficacy, safety, and cost of thrombolytic agents for the management of dysfunctional hemodialysis catheters: a systematic review. Pharmacotherapy. 31, 1031-1040.

Huyut, Z., Beydemir, Ş. and Gülçin, İ. 2017. Antioxidant and Antiradical Properties of Selected Flavonoids and Phenolic Compounds. Biochem. Res. Int. 2017, 7616791.

Jahan, F.N., Rahman, M.S., Hossain, M. and Rashid, M.A. 2008. Antimicrobial activity and toxicity of Quisqualis indica. Orient. Pharm. Exp. Med. 8, 53-58.

Jahan, F.N., Rahman, M.S., Rahman, M.M., Gibbons, S., Masud, M.M., Sadhu, S.K., Hossain, M., Hasan, C.M. and Rashid, M.A. 2009. Diphenylpropanoids from Quisqualis indica Linn. and their anti-staphylococcal activity. Lat. Am. J. Pharm. 28, 279-283.

Kaisar, M.A., Islam, M.R., Rahman, M.S., Hossain, M.K. and Rashid, M.A. 2009. Total phenolic content, free radical scavenging activity and reducing power of Quisqualis indica linn. Dhaka Univ. J. Pharm. Sci. 8, 173-175.

Kulshreshtha, M., Shukla, K.S., Tiwari, G.A., Singh, M.P. and Singh, A. 2018. Pharmacognostical, phytochemical and pharmacological aspects of Quisqualis indica: An update. J. Nat. Sci. Med. 1, 41.

Mahajan, C.P. and Aher, A.N. 2017. A review on ethnobotanical, phytochemical and pharmacological activities of Quisqualis indica Linn. Res. J. Pharmacog. Phytochem. 9, 47-52.

Maroon, J.C., Bost, J.W. and Maroon, A. 2010. Natural anti-inflammatory agents for pain relief. Surg. Neurol. Int. 1, 80-80.

Nigri, G.R., Kossodo, S., Waterman, P., Fungaloi, P. and LaMuraglia, G.M. 2004. Free radical attenuation prevents thrombosis and enables photochemical inhibition of vein graft intimal hyperplasia. J. Vasc. Surg. 39, 843-849.

Nimse, S.B. and Pal, D. 2015. Free radicals, natural antioxidants, and their reaction mechanisms. RSC advances. 5, 27986-28006.
Pisoschi, A.M., Pop, A., Cimpeanu, C. and Predoi, G. 2016. Antioxidant capacity determination in plants and plant-derived products: A review. Oxid. Med. Cell. Longev. 2016, 9130976.

Prasad, S., Kashyap, R.S., Deopujari, J.Y., Purohit, H.J., Taori, G.M. and Daginawala, H.F. 2006. Development of an in vitro model to study clot lysis activity of thrombolytic drugs. Thromb. J. 4, 14.

Rahman, M.S., Begum, B., Chowdhury, R., Rahman, K.M. and Rashid, M.A. 2008. Preliminary cytotoxicity screening of some medicinal plants of Bangladesh. Dhaka Univ. J. Pharm. Sci. 7, 47-52.

Sahu, J., Patel, P.K. and Dubey, B. 2012. Quisqualis indica Linn: A review of its medicinal properties. Int. J. Pharm. Phytopharmacol. Res. 1, 313-321.

Schetter, A.J., Heegaard, N.H. and Harris, C.C. 2010. Inflammation and cancer: interweaving microRNA, free radical, cytokine and p53 pathways. Carcinogenesis. 31, 37-49.

Shilpi, J.A., Islam, M.E., Billah, M., Islam, K.M., Sabrin, F., Uddin, S.J., Nahar, L. and Sarker, S.D. 2012. Antinociceptive, anti-inflammatory, and antipyretic activity of mangrove plants: a mini review. $A d v$. Pharmacol. Sci. 2012, 576086.

Shinde, U., Phadke, A., Nair, A., Mungantiwar, A., Dikshit, V. and Saraf, M. 1999. Membrane stabilizing activitya possible mechanism of action for the antiinflammatory activity of Cedrus deodara wood oil. Fitoterapia. 70, 251-257.

VanWagenen, B.C., Larsen, R., Cardellina, J.H., Randazzo, D., Lidert, Z.C. and Swithenbank, C. 1993. Ulosantoin, a potent insecticide from the sponge Ulosa ruetzleri. J. Org. Chem. 58, 335-337.

Yan, T., Wu, W., Su, T., Chen, J., Zhu, Q., Zhang, C., Wang, X. and Bao, B. 2015. Effects of a novel marine natural product: pyrano indolone alkaloid fibrinolytic compound on thrombolysis and hemorrhagic activities in vitro and in vivo. Arch. Pharm. Res. 38, 1530-1540. 